\title{
The spatial variability of snow resistance on potential avalanche slopes
}

\author{
K. W. BiRKELAND, \\ Department of Geography, Arizona State University, Tempe, Arizona 85287, U.S.A. and \\ Gallatin National Forest Avalanche Center, P.O. Box 130, Bozeman, Montana 59771, U.S.A. \\ K. J. Hansen, \\ Department of Earth Sciences, Montana State University, Bozeman, Montana 59717, U.S.A. \\ R. L. BROWN \\ Department of Civil and Agricultural Engineering, Montana State University, Bozeman, Montana 59717, U.S.A.
}

\begin{abstract}
Since snow avalanches are believed to release from zones of localized weakness, knowledge of snow-strength patterns is important for determining slope stability and for applying effective avalanche-control measures. In this study, the spatial variability of snow resistance (an index of snow strength) and depth were measured and compared with terrain features on two inclined slopes. A refined instrument allowed the strength of an entire snow slab to be characterized in a short time. The spatial pattern of trees appeared to affect the pattern of snow depth at one site, where a significant linear relationship was found between snow depth and average snow resistance. These results suggest that localized snow-depth variations may be important in snow-strength genesis. Although a linear relationship existed at that site, additional factors may be critically relevant. A second site with more complex terrain features and less localized wind drifting did not show a linear relationship between depth and average resistance. Instead, complex patterns of resistance demonstrated that many factors contribute to snow resistance. In particular, the snow overlying rocks was found to have significantly weaker resistance than that in adjacent areas not over rocks.
\end{abstract}

\section{INTRODUGTION}

It has been proposed that avalanches result when localized weak zones (described as having weak shear strength) within a snow slab fail initially, imparting rapid increases in stress and triggering full slab failure (Gubler, 1977; Smith and Sommerfeld, 1985; Gubler and Bader, 1989). Since control techniques may be ineffective unless applied to these weaker areas of the $\cdot$ snow, improper placement of explosives may give a false sense of security and has been advanced as a major cause of "post-control release" avalanches that run minutes to hours after avalanche control measures have been applied (Williams, 1978). Thus, knowledge of the number, size, distribution and magnitude of weaker areas of the snowpack may be critical for forecasting slope stability.

Previous field studies confirm the existence of large variations in snowpack strength over short distances, but little improvement has been made in the prediction of where stronger and weaker areas of a particular slope may be located. In-situ field measurements of localized shear-strength variability utilizing a shear frame found both weaker and stronger areas, and these variations were hypothesized as being due to local wind patterns during snow deposition (Conway and Abrahamson, 1984). Subsequent work suggested that a "deficit", or weak area, along a crown of a recent avalanche may vary in length from 2.9 to $7 \mathrm{~m}$ (Conway and Abrahamson, 1988).

Using slightly modified methods, Föhn (1988) found shear-strength fluctuations two to four times smaller than those reported by Conway and Abrahamson (1984), and speculated that larger and/or more numerous weak areas were necessary for avalanche initiation. Föhn (1988) also hypothesized that strength variations on lee slopes were due to wind influences, but noted that strength patterns across more homogeneous slopes were seemingly random.

In addition to shear-frame measurements, Rutschblock tests (Föhn, 1987) have been used to investigate snow-strength variability. Föhn (1988) took multiple Rutschblock tests over a slope and determined that largescale strength variability existed on some slopes. Similarly, Jamieson and Johnston (1992, 1993) found variations in Rutschblocks over small slopes, concluding that Rutschblock numbers and variability were higher near the top of slopes.

Although field data have been collected related to the existence of weaker and stronger areas of the snowpack, and wind influences have been postulated to affect 
strength patterns, few data have been gathered pertaining to the cause of relatively weaker areas within potential avalanche slopes. Snow studies in Montana, U.S.A., in the late 1960 s and early 1970 s, using sample intervals of $15 \mathrm{~m}$ or more, correlated variability in resistance (a snowstrength index) of snowpack to location of early-season snow (personal communication from C. Bradley, 1988). Areas retaining early-season snow cover (i.e. north-facing slopes and areas under trees) were found to be more susceptible to basal weakness due to increased facetedcrystal growth.

In order to address this lack of data about the formation of weaker and stronger areas in snow, the objectives of this study are: (1) to determine if snowresistance variations across a slab can be identified and measured, and (2) to correlate the physical characteristics of the study site (specifically, the location of rocks and trees) with snow resistance. It should be emphasized, however, that it is unclear what may be the relationship between spatial patterns of resistance, measured in this study, and shear-strength patterns, which are believed to be critical for avalanche release. Field measurements indicate that as many as $60 \%$ of all slab failures may be due to unmeasurably thin, weak interfaces (Föhn, 1992); these interfaces, as well as other weak layers thinner than about $2 \mathrm{~cm}$, are not discernible by the Digital Resistograph (DR) (Birkeland, 1990; Brown and Birkeland, 1990) used in this study. Despite this basic problem, knowledge of patterns of resistance will provide a useful first step in understanding overall snow-strength variations on a given slope. Furthermore, understanding these variations may eventually be important for assessing slope stability, since an investigation of several avalanche accidents in Colorado, U.S.A., revealed that slides were triggered from zones of localized overall-snowpack weakness (Logan, 1992).

\section{FIELD AREA}

Two sites near Bozeman, Montana, U.S.A. (approximately $45^{\circ} 45^{\prime} \mathrm{N}, 111^{\circ} \mathrm{W}$ ), and close to Bridger Bowl ski area, were studied (Fig. 1). The sites (Bradley Meadows and Bridger Bowl) were chosen for easy access and safety and because they have similar aspects $\left(60-80^{\circ}\right.$ east of north), elevations $(2300 \mathrm{~m})$ and slope angles $\left(32-36^{\circ}\right)$. The spatial distribution of rock outcrops, vegetation and wind exposure, however, varies between the two areas, allowing a comparison of study sites based on those factors. The Bridger Bowl site has been used for several past studies (Dent and Lang, 1980; Lang and Dent, 1980; Grady, 1982; Grady and others, 1982; Brown and Hansen, 1987). It has greater on-site variation than the Bradley Meadows site, with several trees, a steep rock outcrop and many large loose rocks (Table 1).

\section{METHODS}

A Digital Resistograph (DR) (Birkeland, 1990; Brown and Birkeland, 1990), a modified version of the DigitalThermo Resistograph (Dowd and Brown, 1986), which is based on the original mechanical resistograph (Bradley,

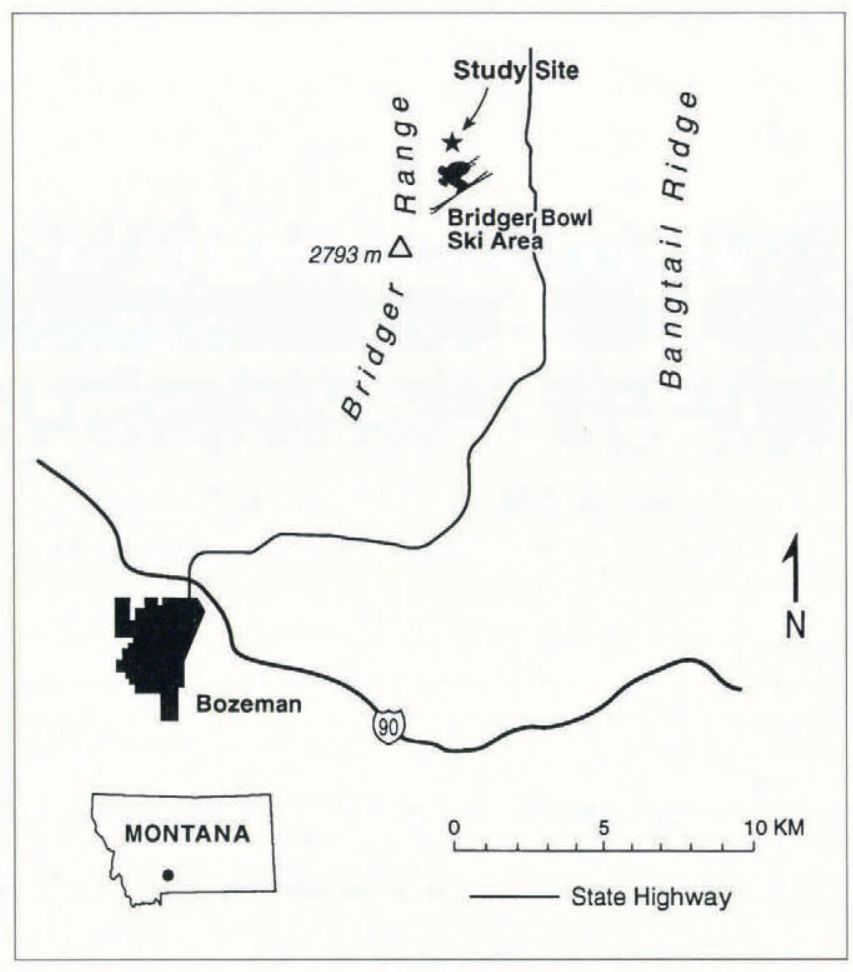

Fig. 1. The two study sites are located directly north of Bridger Bowl ski area, which is $19 \mathrm{~km}$ northeast of Bozeman, Montana, U.S.A.

1966), was used for this study. The DR is pushed manually through the snow and returns a string of resistance values at $0.005 \mathrm{~m}$ intervals to a field computer. The DR was an appropriate instrument for this study because: (1) it provided an index of snow strength, permitting the characterization of snow-strength variability

Table 1. Slope characteristics of the study sites

\section{Slope characteristics Bradley Meadows Bridger Bowl}

$\begin{array}{lll}\text { Similarities } & & \\ \text { Aspect } & 60^{\circ} \text { east of north } & 80^{\circ} \text { east of north } \\ \text { Elevation } & 2300 \mathrm{~m} & 2300 \mathrm{~m} \\ \text { Slope angle } & 34^{\circ} & 32-36^{\circ}\end{array}$

\section{Differences}

$\begin{array}{ll}\text { Wind exposure } & \text { Exposed } \\ \text { Trees } & \text { A few stan }\end{array}$

A few stands surround the site, up to $24 \mathrm{~m}$ tall

Rock outcrop None

Substrate

$$
\begin{aligned}
& \text { Predominantly } \\
& \text { grass-covered } \\
& \text { soil, some small } \\
& \text { rocks (less than } \\
& 1 \mathrm{~m}^{2} \text { ) }
\end{aligned}
$$

Sheltered

A few stands within the site, and many trees surrounding the site; up to $22 \mathrm{~m}$ tall

One significant rock outcrop (approx. $64 \mathrm{~m}^{2}$ ) Soil, with some large boulders (up to $8 \mathrm{~m}^{2}$ ) interspersed throughout 
on a slope, (2) each measurement took less than a minute, allowing many data points to be collected (in contrast to previous methods which were time-consuming), (3) the measurements were comparable to those of the commonly used ram penetrometer (Down and Brown, 1986; Brown and Birkeland, 1990) and (4) the data were collected in a form that enabled them to be easily loaded on to and analyzed with a computer.

Sites were permanently marked for sampling, and detailed topographic maps constructed that included the locations of rocks and trees around and within the sites. Each site was sampled only once per winter for the two study seasons, due to the considerable disturbance of the snowpack that occurred during sampling. The selection of sampling dates was based on: (1) the existence of a well-developed, typically mid-season snowpack with discernible weaker and stronger layers (identified by examining a snow profile) and (2) a weather pattern indicating relative stability (little chance for major temperature changes, wind, precipitation, or other factors that would cause rapid snowpack changes) over the $1-4 \mathrm{~d}$ required for sampling a specific site.

Sampling was done in a $1 \mathrm{~m} \times 1 \mathrm{~m}$ grid across and downslope at the site. Control profiles were taken during sampling to track any change in the instrument or snow conditions. Between 300 and 1100 snow profiles were sampled per site. Data were analyzed on a MicroVAXII computer using the "S" statistical software (Becker and others, 1988). Each profile was plotted initially to discern snow-cover characteristics at specific sites and to track weak and strong layers visually across and down the slope. Data were collapsed into depth-normalized average resistance by averaging the string of resistance values returned by the DR, and then dividing by the total depth for that sample point. These average resistance values were then smoothed until overall characteristics could be discerned, and then the data were mapped in three dimensions. Three-dimensional maps of depth and resistance were created in the same manner for each site for comparison.

Simple linear regression was used on data sets before smoothing to quantify the extent of the correlation between snow depth and average snow resistance. The regression equation used was of the form (Neter and others, 1990):

$$
y=\beta_{0}+\beta_{1} x_{1}
$$

where $y$ is average resistance, $x_{1}$ is snow depth, and $\beta_{0}, \beta_{1}$ are constants. P-values reported are the probability that no relationship exists between the variables (i.e. the probability that $\beta_{1}=0$ ). Values of $r^{2}$ are the proportion of the total variation of average resistance that is explained by the regression of average resistance on depth (Barber, 1988). In other words, the p-value demonstrates the significance of the relationship between the variables, while the $r^{2}$ value indicates the predictive value of the regression equation.

Since the response variable $y$ (average resistance) may be spatially correlated with itself, applying least-squaresregression analysis to these data may yield p-values that are underestimated (Neter and others, 1990). This is a common problem with the analysis of spatial data. Still, regression is considered a "robust" statistical technique whereby meaningful results can be obtained even when the assumption of independence is violated (Neter and others, 1990). To decrease the effects of spatial autocorrelation, data sets were analyzed both in their original form with 300-600 observations and in a reduced form of 30-40 observations. Reduction in the data sets was accomplished by taking the values in approximately every fifth row and column.

Maps of site characteristics were visually compared with resistance maps to recognize obvious patterns. Multiple-regression techniques were used to quantify the relationship between rocks and resistance using the following equation (Neter and others, 1990):

$$
y=\beta_{0}+\beta_{1} x_{1}+\beta_{2} x_{2}+e
$$

where $y$ is average resistance, $x_{1}$ is snow depth, $x_{2}$ is an indicator variable indicating the presence or absence of rocks underlying snow at that point (i.e. $x_{2}=0$ in areas without rocks and $x_{2}=1$ in areas with rocks), and $\beta_{0}$, $\beta_{1}, e$ are constants.

This test controlled for depth, allowing the analysis to focus on the effect of the presence of rocks underlying the snow. The p-values reported for multiple regression are the probability that $x_{2}$ does not help explain the variability of resistance. Thus, a low p-value indicates that the presence of rocks does help to explain resistance variability.

A large number of erroneous data points, attributable to clogging of the probe, precluded the use of multipleregression analysis for the first year's data at the Bridger Bowl site. The absence of rocks also made this test inapplicable at the Bradley Meadows site. Thus, only the second season's data at the Bridger Bowl site were used for a multiple-regression analysis focusing on the effect of rocks on snow resistance.

\section{RESULTS AND DISCUSSION}

\section{Relationship of snow depth to site characteristics}

Snow-depth data gathered from the two field seasons showed discernible variations at both study sites (Table 2 ). However, the relationship between snow depth and site characteristics varied between the Bradley Meadows and Bridger Bowl sites. Both areas received strong southerly winds during both field seasons (Birkeland, 1990). At the Bradley Meadows site, results for the two seasons indicated that snow-depth patterns were related to wind-induced drift patterns around trees upwind of the study site (Figs 2, 3 and 4). Conversely, at the Bridger Bowl site there was no similarity between the location of trees within and around the site and snow depth in 198889 (Figs 5 and 6); similar results were observed in 1989 90 (Birkeland, 1990). This contrast is due to site location. The Bradley Meadows site is at the edge of an exposed meadow, whereas the Bridger Bowl site has enough large trees around it to be protected from wind-induced drifting and scouring at the snow surface. Thus, wind-drifted and eroded areas can be observed at the exposed Bradley Meadows site but not at the Bridger Bowl site.

Lower depths were observed over some areas with rocks at the Bridger Bowl site. Some decreases in depth 
Table 2. Maximum, minimum, mean and standard deviation for snow depth at the time of sampling for the Bradley Meadows and Bridger Bowl sites

\begin{tabular}{|c|c|c|c|c|c|c|}
\hline \multirow[t]{3}{*}{ Site, year } & \multirow[t]{3}{*}{ Sampling dates } & \multirow[t]{3}{*}{ Number $(n)$} & \multicolumn{4}{|c|}{ Snow depth } \\
\hline & & & Maximum & Minimum & Mean & Standard deviation \\
\hline & & & $\mathrm{cm}$ & $\mathrm{cm}$ & $\mathrm{cm}$ & \\
\hline \multicolumn{7}{|c|}{ Bradley Meadows } \\
\hline 1988-89 & 25-26 February & 358 & 198 & 102 & 147.3 & 19.0 \\
\hline $1989-90$ & 10 March & 300 & 186 & 66 & 122.6 & 27.3 \\
\hline \multicolumn{7}{|l|}{ Bridger Bowl } \\
\hline $1988-89$ & 5-7 March & 657 & 232 & 76 & 165.9 & 28.2 \\
\hline 198990 & 14-15 January & 616 & 161 & 32 & 119.8 & 15.6 \\
\hline
\end{tabular}

are attributable to the influence of a steep rock outcrop that allowed the snow to sluff off, and a large loose boulder that was shallowly buried. However, these areas were small and are not apparent in final maps due to smoothing processes used.

\section{Relationship of snow depth to average resistance}

Like snow depth, average resistance showed discernible

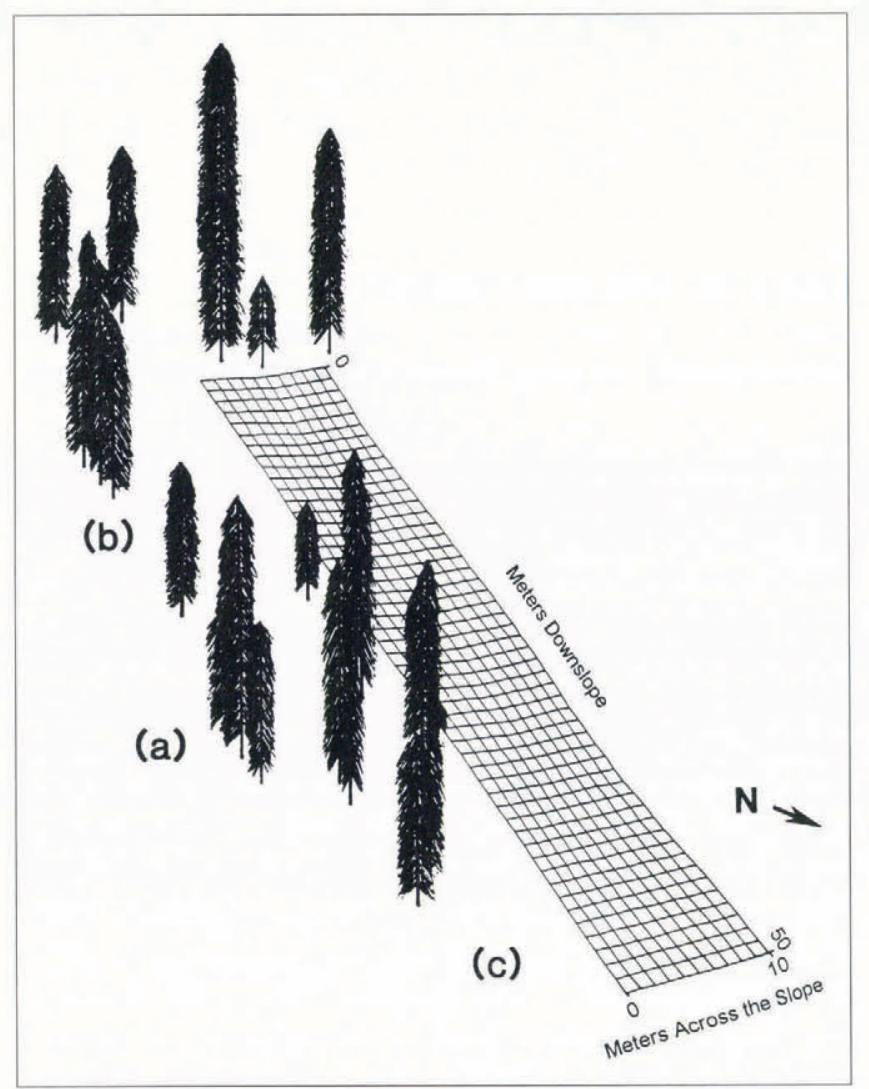

Fig. 2. Topography of the Bradley Meadows site. Several groups of trees are immediately adjacent to the site. The largest group of trees is present at mid-slope (a), there is a gap in the trees at point (b), and (c) indicates an area unprotected by trees. variations at both sites (Table 3 ). However, the relationship between snow depth and average resistance varied between the two sites. Visual comparison of threedimensional plots for depth and resistance indicates no
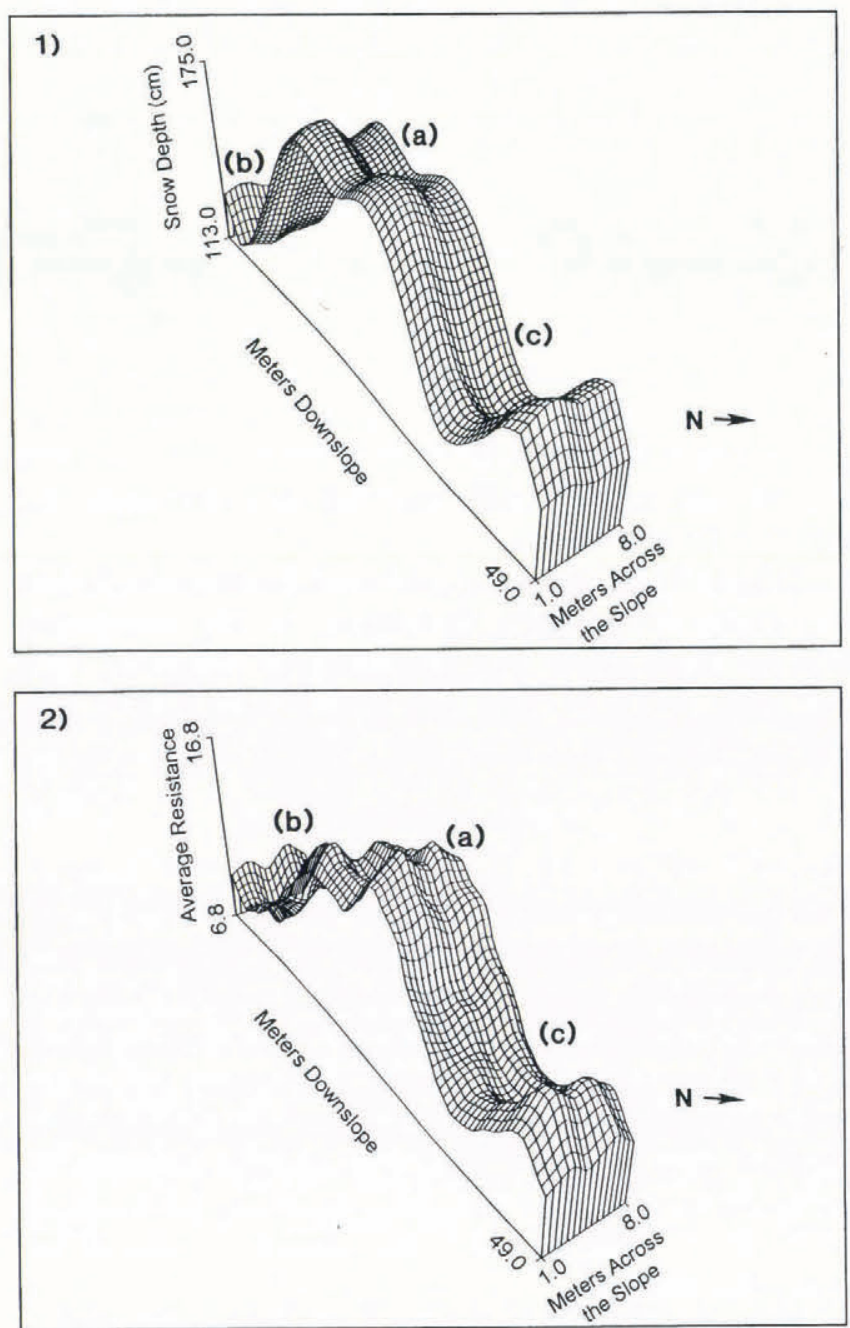

Fig. 3. Three-dimensional perspective plots for depth (1) and average resistance (2) at the Bradley Meadows site in 1988 89. Points (a) indicate a snowdrift and increased resistance, whereas (b) and (c) indicate areas of wind scour, decreased depth and decreased resistance. 

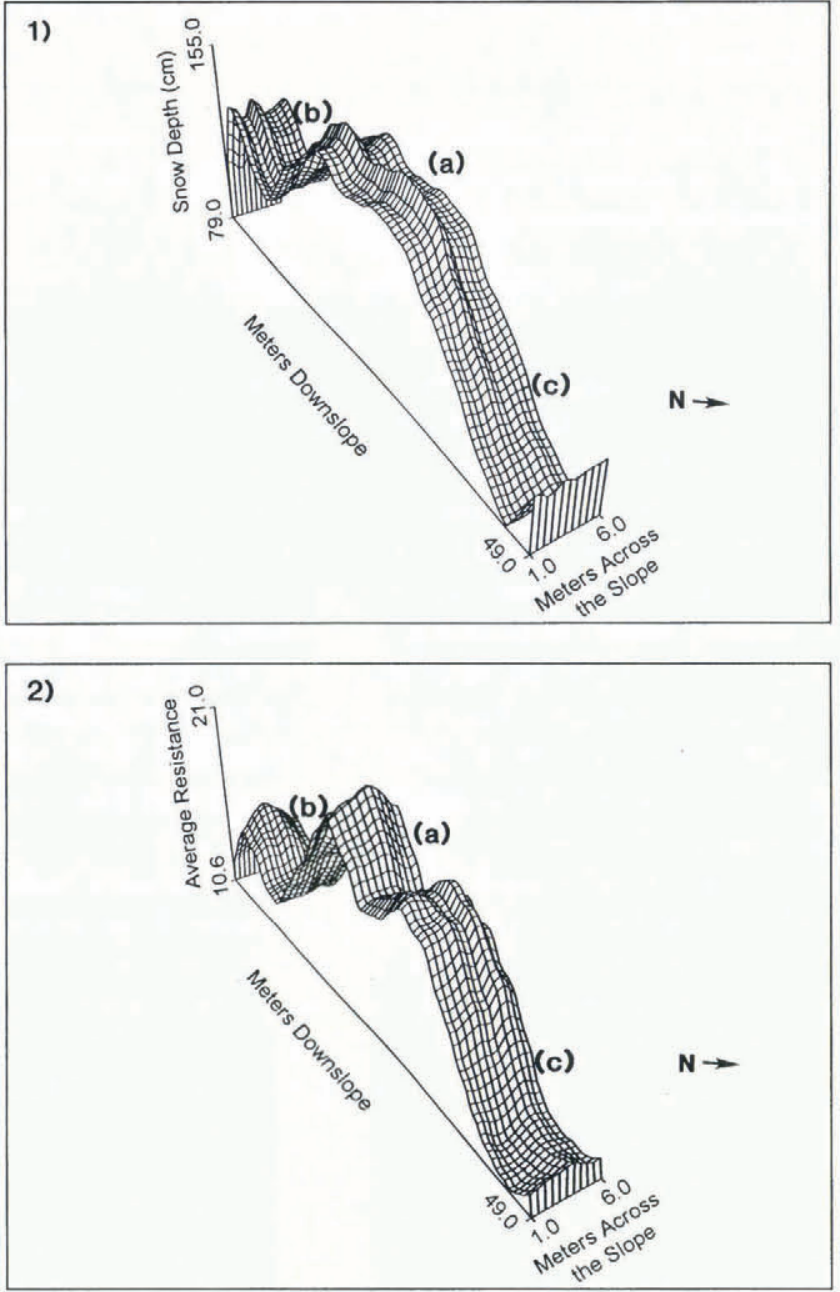

Fig. 4. Three-dimensional perspective plots for depth (1) and average resistance (2) at the Bradley Meadows site in 1989-90. Results are similar to the previous year and demonstrate a relationship between depth and average resistance at this site.

relationship between depth and average resistance for the Bridger Bowl site for 198889 (Fig. 6). After the data sets were reduced in order to lessen the effects of autocorrelation, linear regression showed the relationship was statistically insignificant ( $\mathrm{p}$-value $>2 \times 10^{-1}$ ) (Fig. 7). Data for 1989-90 were similar (Birkeland, 1990). This contrasts markedly with the Bradley Meadows site where visual comparison of both depth and average resistance (Figs 3 and 4) and statistical evidence show a highly significant relationship (p-values $<7 \times 10^{-3}$ ) (Fig. 8). However, low $r^{2}$ values $\left(r^{2}<0.15\right)$ at that site indicate that, not surprisingly, many factors other than depth are critical to snow strength. Similar to the relationship between snow depth and site characteristics, differences between sites help to explain the different results. The Bradley Meadows site is relatively homogeneous, with a consistent slope and uniform substrate; the only major variability is snow depth, which appears to be controlled by drifting around trees adjacent to the site. In contrast, the Bridger Bowl site is more complex due to the many trees and rocks located within and around it. The trees and rocks locally affected resistance, and there were no definite snowdrifts adjacent to trees. Thus, any relationship that may have been observable between depth and

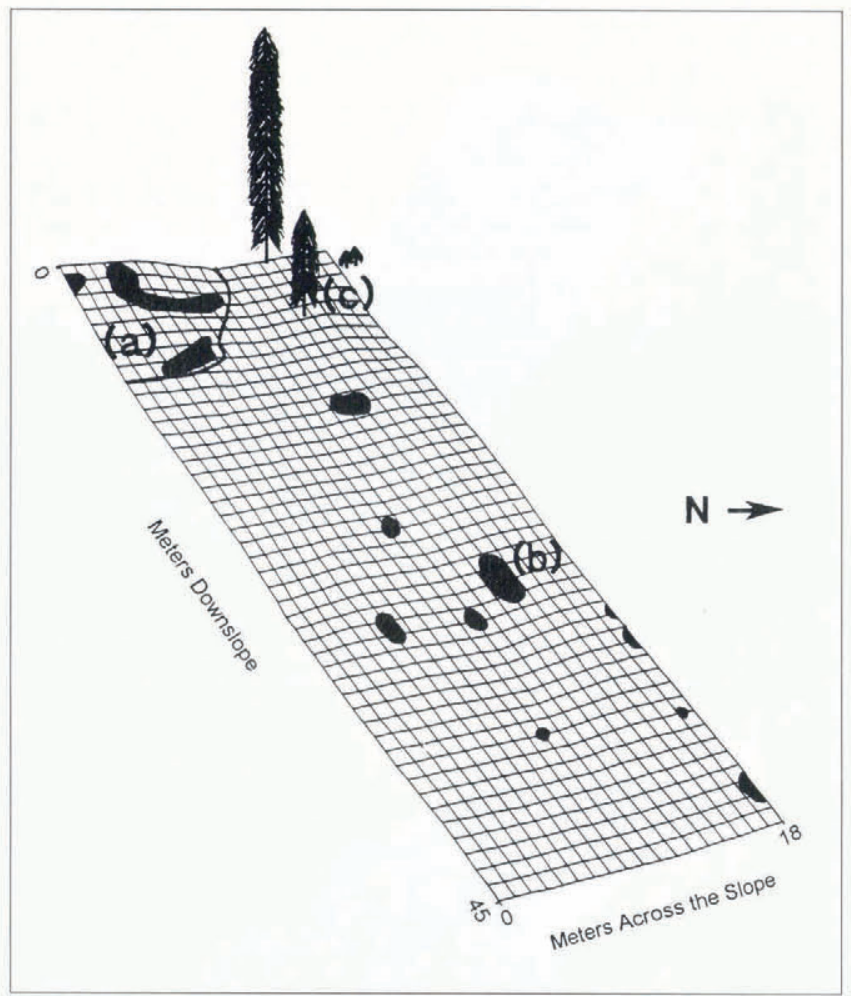

Fig. 5. Topography and geographic variability within the Bridger Bowl site. Shaded areas represent rocks, including a rock outcrop (a), some large, loose boulders (the largest of which is at (b)) and two small groups of trees.

average resistance at the Bridger Bowl site appears to be muted by other variables.

A relationship does, however, appear to exist between depth and average resistance data collected at the Bradley Meadows site in both years (Figs 3 and 4). Snow depth is an important factor in snowpack genesis; snow insulates the warmer ground (which stays close to $0^{\circ} \mathrm{C}$ (McClung and Shaerer, 1993)) from the cold air above. Shallow areas will have greater temperature gradients than nearby deeper areas. Larger temperature gradients result in higher vapor-pressure gradients which produce weak, faceted snow crystals with low resistance. Snow depth, therefore, appears to be an important factor for spatial variability of average snow resistance at the Bradley Meadows site, and may also be important in other locations where wind deposition causes considerable small-scale variations in snow depth.

Temperature gradients can be calculated for the areas of maximum and minimum depth at the Bradley Meadows site in 1988-89 as examples of spatial variations in localized temperature gradients. At the time of sampling, the maximum snow depth was $198 \mathrm{~cm}$ and the minimum was $102 \mathrm{~cm}$. Using $-12.4^{\circ} \mathrm{C}$ as the ambient air temperature (this was the average temperature for February 1989 (Birkeland, 1990)), and assuming a ground temperature of $0^{\circ} \mathrm{C}$ (McClung and Shaerer, 1993), the temperature gradient at the place of maximum depth was $6.3^{\circ} \mathrm{Cm}^{-1}$, while the temperature gradient at the place of minimum depth was $12^{\circ} \mathrm{Cm}^{-1}$. Faceted-crystal growth is dependent on vapor-pressure gradients, which in turn depend largely on temperature gradients. The temperature gradient of $10^{\circ} \mathrm{Cm}^{-1}$ is commonly cited as the level at which faceted-crystal 


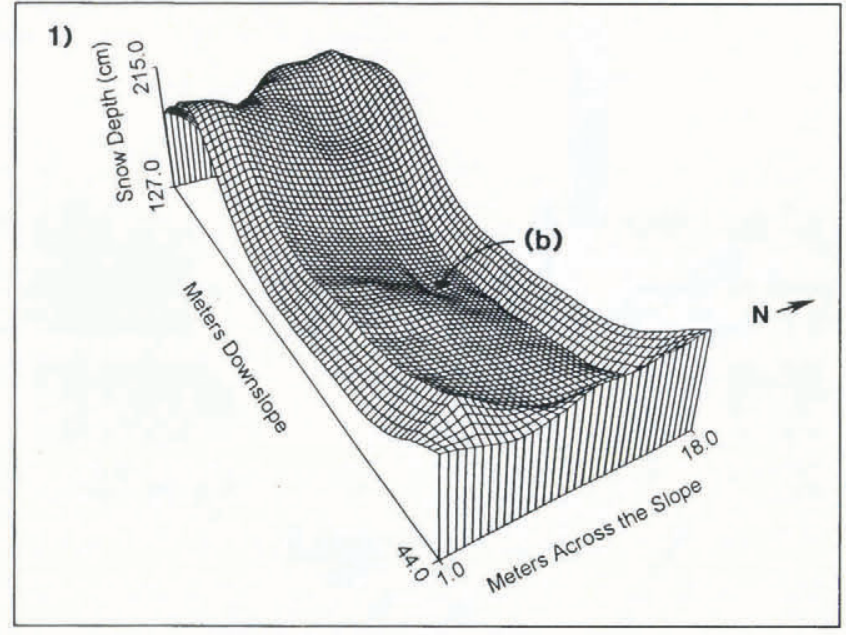

2)

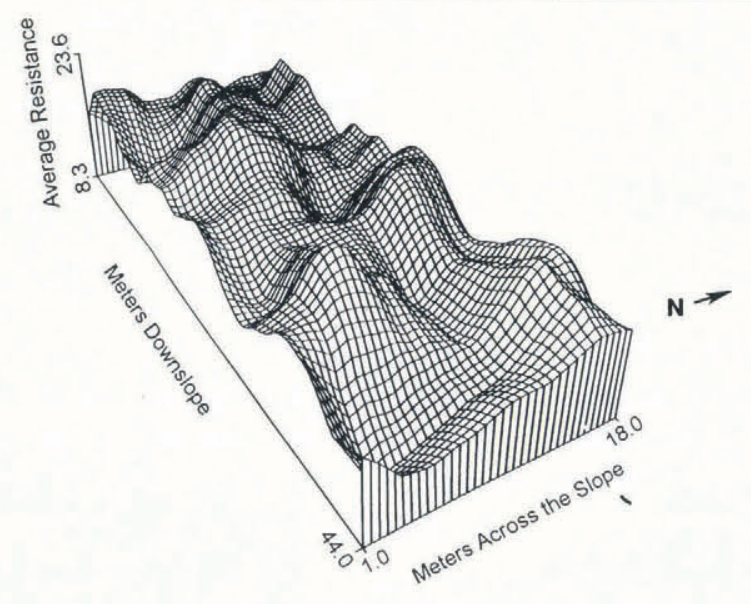

Fig. 6. Three-dimensional perspective plots for depth (1) and average resistance (2) at the Bridger Bowl site in 1988-89. Point (b) indicates the largest rock which has only a thin cover of snow. Little relationship between depth and average resistance can be observed. Similar results were obtained in 1989-90.

growth dominates over other processes (Perla and Martinelli, 1976; McClung and Shaerer, 1993). Thus, in this relatively small site there can be areas that are well within the realm of faceted-crystal growth while nearby areas do not have the temperature gradients necessary for faceted-crystal growth.

\section{Relationship of site characteristics to average resistance}

Certain site characteristics may affect average resistance locally. A multiple regression at the Bridger Bowl site yielded the following equation:

$$
y=8.88+0.039 x_{1}-6.56 x_{2}
$$

where $y$ is average resistance, $x_{1}$ is snow depth and $x_{2}$ is an indicator variable indicating the presence or absence of rocks underlying the snow (i.e. $x_{2}=0$ where there are no rocks and $x_{2}=1$ where rocks are present). The standard error for the indicator variable was 0.77 , the $t-$ statistic was -8.52 and the p-value was less than $10^{-6}$, indicating there is a strong relationship between the presence of underlying rocks and lower values of average resistance at this site. Such a relationship is not apparent visually (Figs 5 and 6) because smoothing functions applied to the data for graphical purposes washed out small-scale differences.

Several mechanisms for this relationship between rocks and decreased resistance can be hypothesized. First, many of the rocks at the Bridger Bowl site are large, and observations at the site indicated that those rocks were wholly buried by snow later in the season than adjacent non-rock areas and were associated with a thinner snowpack. This would locally increase the tem-perature gradient, facilitating faceted-crystal growth and decreasing the resistance over rocks. Secondly, air pockets that exist around the base of some rocks would increase the area available for water-vapor transport and allow room for faceted crystals to grow. Finally, rocks may simply be more efficient than soil in transferring heat to the snow.

\section{Variabilities in snow properties due to depositional differences}

Field observations at Bradley Meadows during wind events indicated that the area of increased snow depth downwind of the trees was a result of wind-deposited snow, while the shallower areas at that site were scoured during wind events. Thus, the snow left in those shallower areas can be attributed to snowfall without much wind. Depositional differences, such as whether the snow in a particular area was deposited primarily by wind events or

Table 3. Maximum, minimum, mean and standard deviation for average resistance at the time of sampling for the Bradley Meadows and Bridger Bowl sites

$$
\text { Site, year Sampling dates Number }(n)
$$

Average resistance (resistance numbers)
Maximum
Minimum
Mean

\begin{tabular}{|c|c|c|c|c|c|c|}
\hline \multicolumn{7}{|c|}{ Bradley Meadows } \\
\hline 1988-89 & 25-26 February & 358 & 31.0 & 1.26 & 12.7 & 5.54 \\
\hline $1989-90$ & $10 \mathrm{March}$ & 300 & 29.0 & 4.84 & 15.4 & 4.25 \\
\hline \multicolumn{7}{|l|}{ Bridger Bowl } \\
\hline $1988-89$ & 5-7 March & 657 & 38.9 & 1.21 & 14.4 & 8.34 \\
\hline 198990 & 14-15 January & 616 & 28.8 & 1.05 & 12.8 & 5.31 \\
\hline
\end{tabular}
Standard deviation 


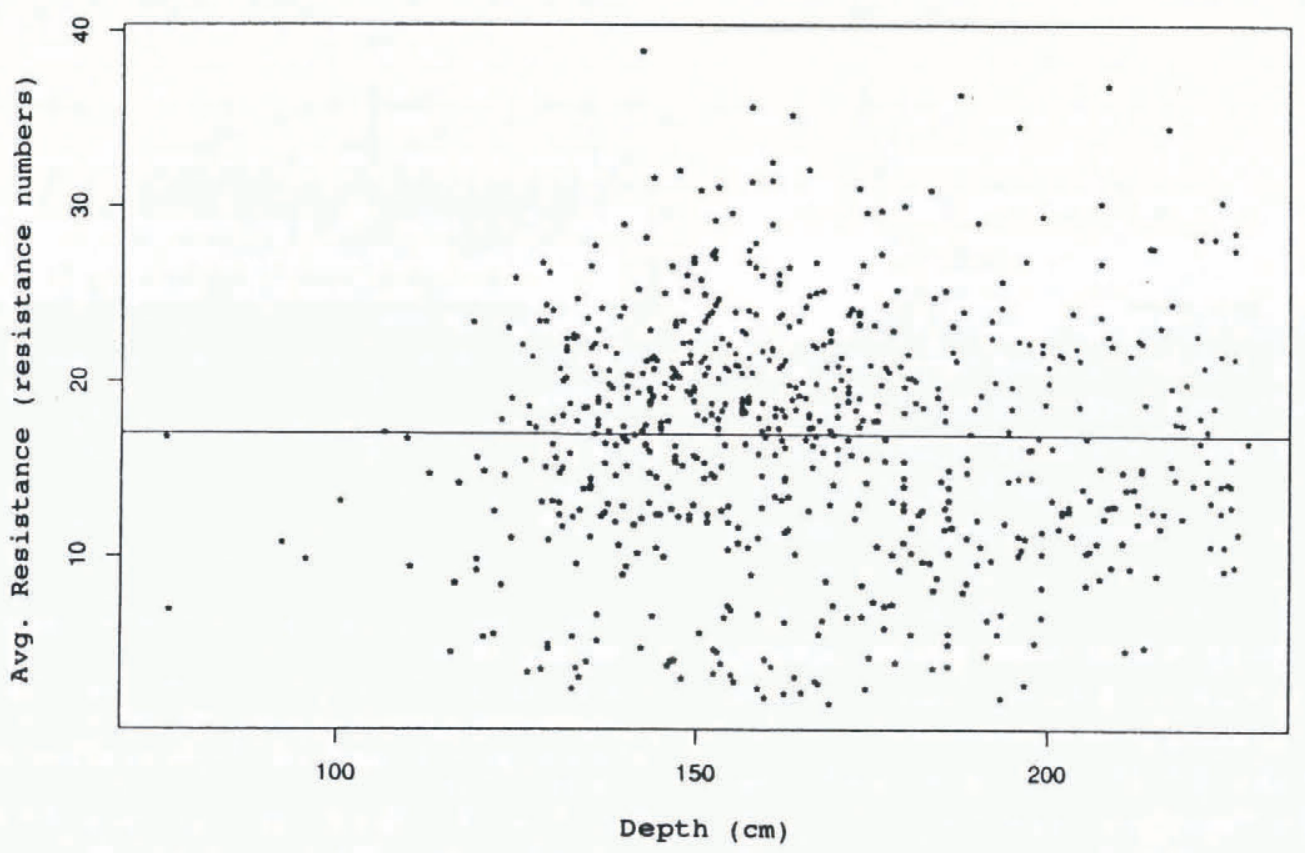

Fig. 7. A simple linear regression between snow depth and average resistance for the Bridger Bowl site in $1988-89$ was insignificant $(p$-value $=0.4505)$. Similar results were obtained in 1989-90.

by snowfall, may also be important in explaining snowresistance variability at the site.

Wind-deposition patterns related to trees at the site during both winters may have helped to create stronger resistance due to three factors. First, as discussed previously, increased depth would decrease the temperature gradient, thereby restricting faceted-crystal growth. Secondly, wind deposition increases the density of snow due to the mechanical breaking of snow grains into smaller particles that become more tightly packed during deposition (Prowse and Owens, 1984). Such increased densities limit the pore space available for the growth of faceted crystals and lead to a higher resistance both immediately after deposition and later. Finally, since denser snowpacks have higher conductivities, they conduct heat more efficiently, thereby maintaining lower temperature gradients and reducing the potential for faceted-crystal growth and the formation of a weaker snowpack.

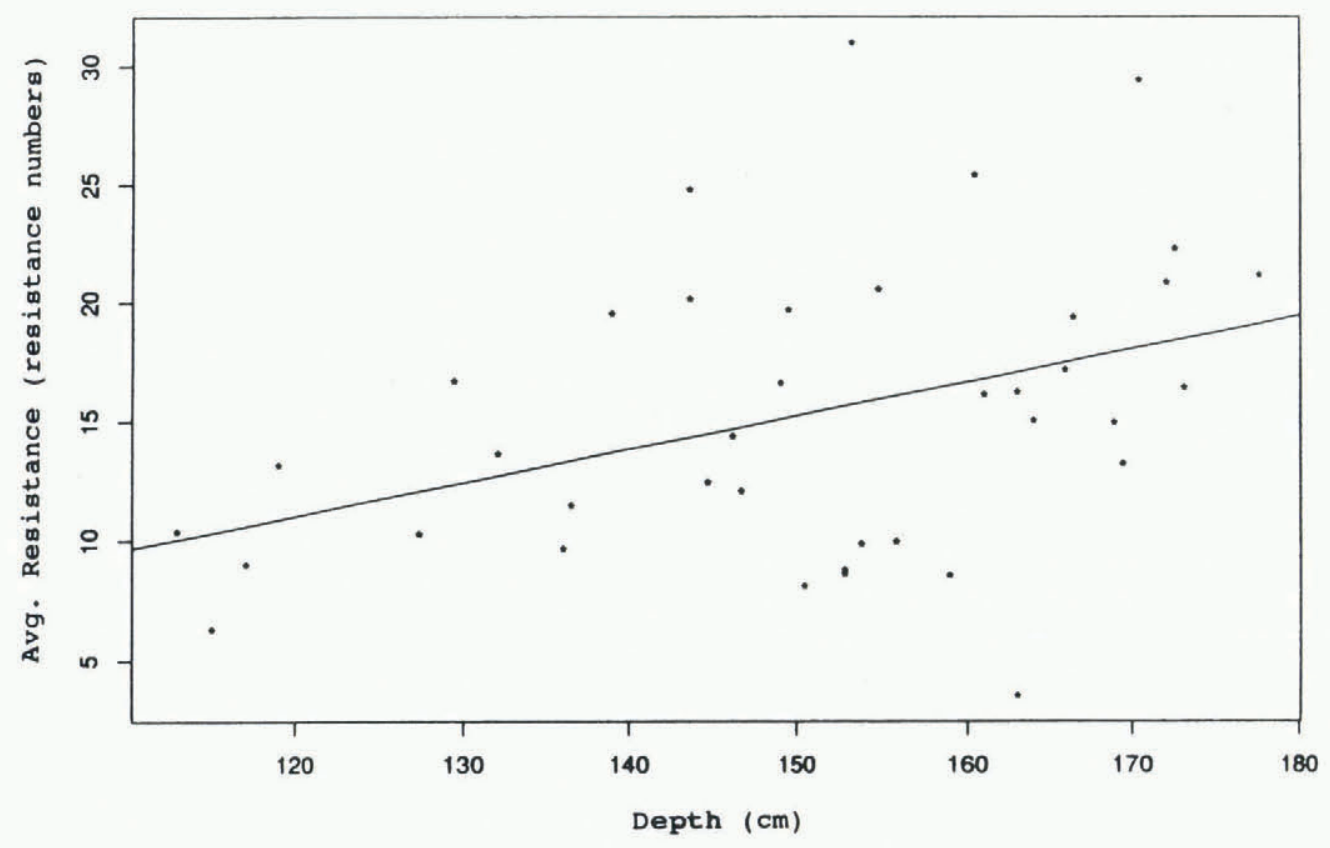

Fig. 8. A simple linear regression between snow depth and average resistance for the Bradley Meadows site in $1988-89$ with a data set reduced from $n=358$ to $n=39$ to lessen the effects of autocorrelation. A significant relationship exists ( $p$ value $\left.=7 \times 10^{-3}\right)$, but the predictive value of the relationship is low $\left(r^{2}=0.15\right)$. The regression equation is $y=$ $-5.54+0.14 x$ where $y$ is average resistance and $x$ is depth. The standard error for $x$ is 0.06 , the t-statistic is 2.41 and the p-value is 0.007; the standard error for the intercept is 8.59, the t-statistic is -0.64 and the p-value is 0.52. Thus, the slope is significant, but the intercept is not. 


\section{Summary}

The refined Digital Resistograph allowed the resistance of snowpack on a slope to be characterized by many measurements in a relatively short time period. Results at the Bradley Meadows site suggest a relationship between tree locations, wind patterns and snow depth. Although this site also showed a significant relationship between snow depth and average snow resistance, low $r^{2}$ values indicate that several compounding factors may be important. The conclusion that many factors affect resistance is reinforced by results at the Bridger Bowl site, which showed no relationship between depth and average resistance. This site has more complex site characteristics which may have affected resistance, especially many rocks which were shown through multiple-regression analysis to be significantly related to areas of weaker resistance.

Additional avenues for future research can be suggested. First, and perhaps most importantly, to analyze the individual layers within the snowpack an in-depth analysis of resistance-profile data is needed, instead of the average resistance of the entire thickness. Secondly, the relationship between site characteristics and snow resistance could be better understood by studying more sites with a larger variety of such features. The effects of rocks on snowpack resistance warrant further analysis. Thirdly, it would be useful to study further the relationship between snow depth and average resistance because, if they are strongly related under certain weather conditions, then estimation of resistance might be possible by measuring depth and monitoring the specific weather conditions. Finally, it might be useful to explore the relationship of average resistance patterns to slope stability. Although variations in shear strength, which are believed to be critical for slab failure, cannot be related to variations in average resistance, field observations have indicated that aval-anches are sometimes initiated from zones which have lower average resistance (Logan, 1992). Someday, resistance data of a slope may be one input to a computer model which would take into account weather, snowpack and other factors to help assess slope stability.

\section{ACKNOWLEDGEMENTS}

Financial support for this work was provided by a U.S. National Science Foundation Graduate Fellowship, Sigma Xi, Montana State University, and the Montana Technological Development Trust. J. Banfield and W. Quimby provided statistical consulting. P. Birkeland, K. Elder, D. McClung and an anonymous reviewer provided helpful critiques of the manuscript.

\section{REFERENCES}

Barber, G. M. 1988. Elementary statistics for geographers. New York, Guiliford Press.
Becker, R. A., J. M. Chambers and A. R. Wilks. 1988. The new S language: a programming environment for data analysis and graphics. Pacific Grove, CA, Wadsworth and Brooks/Cole Advanced Books and Software.

Birkeland, K. W. 1990. The spatial variability of snow resistance on potential avalanche slopes. (M.S. thesis, Montana State University.)

Bradley, C. C. 1966. The snow resistograph and slab avalanche investigations. International Association of Scientific Hydrology Publications 69 (Symposium at Davos 1965 - Scientific Aspects of Snow and Ice Avalanches), 251-260.

Brown, R. L. and K.W. Birkeland. 1990. A comparison of the digital resistograph with the ram penetrometer. Proceedings of the 1990 International Snow Science Workshop, Bigfork, Montana, 19-30.

Brown, R. L. and A. Hansen. 1987. Field studies on stress waves in natural snowcover. In Kry, P. R., comp. Snow Property Measurement Workshop, April 1-3, 1985, Chateau Lake Louise, Alberla, Canada. Ottawa, National Research Council of Canada, 89-110. (Technical Memorandum 140.

Conway, H. and J. Abrahamson. 1984. Snow stability index. J. Glaciol., 30 (106), 321-327.

Conway, H. and J. Abrahamson. 1988. Snow-slope stability-a probabilistic approach. J. Glaciol., 34(117), 170-177.

Dent, J. D. and T.E. Lang. 1980. Modeling of snow flow. f. Glaciol., 26 (94), 131-140.

Dowd, T. and R. L. Brown. 1986. A new instrument for determining strength profiles in snow cover. f. Glaciol., 32(111), 299301.

Föhn, P. M. B. 1987. The "Rutschblock" as a practical tool for slope stability evaluation. International Association of Hydrological Sciences Publication 162 (Symposium at Davos 1986-Avalanche Formation, Movement and Effects), $223-228$.

Föhn, P. M. B. 1988. Snowcover stability tests and the areal variability of snow strength. Proceedings of the 1988 International Snow Science Workshop, Whistler, British Columbia, Canada, 262273.

Föhn, P. M. B. 1992. Characteristics of weak snow layers or interfaces. Proceedings of the 1992 International Snow Science Workshop, Breckenridge, Colorado, $160-170$.

Grady, T.R. 1982. The effects of snow compaction on water release and sediment vield. (M.S. thesis, Montana State University.

Grady, T. R., S. G. Custer and J. Montagne. 1982. The effects of snow compaction on water release and sediment yield, Bridger Bowl Ski Area, Gallatin County, Montana. Bozeman, MT, Montana State University. (Montana Resources Research Center Report 124.)

Gubler, H. 1977. Artificial release of avalanches by explosives. $\mathcal{F}$. Glaciol., $19(81), 419429$.

Gubler, H. and H. -P. Bader. 1989. A model of initial failure in slabavalanche release. Ann. Glaciol., 13, 90-95.

Jamieson, B. and C. Johnston. 1992. Experience with rutschblocks. Proceedings of the 1992 International Snow Science Workshop, Breckenridge, Colorado, $150-159$.

Jamieson, B. and C. Johnston. 1993. Rutschblock precision, technique variations and limitations. J. Glaciol., 39(133), 666-674.

Lang, T. E. and J.D. Dent. 1980. Scale modeling of snow-avalanche impact on structures. F. Glaciol., 26(94), 189-196.

Logan, N. 1992. Snow temperature patterns and artificial avalanche release. Proceedings of the 1992 International Snow Science Workshop, Breckenridge, Colorado, 37-46.

McClung, D. M. and P. A. Shaerer. 1993. The avalanche handbook. Seattle, WA, The Mountaineers.

Neter, S., W. Wasserman and M. Kutner. 1990. Applied linear statistical models. Boston, MA, Irwin.

Perla, R. I. and M. Martinelli, Jr. 1976. Avalanche handbook. Washington, DC, U.S. Department of Agriculture. (Handbook 489. )

Prowse, T. D. and I. F. Owens. 1984. Characteristics of snowfalls, snow metamorphism, and snowpack structure with implications for avalanching, Craigieburn Range, New Zealand. Arct. Alp. Res., 16 (1), 107-118.

Smith, F. W. and R.A. Sommerfeld. 1985. The simulation of the statistical failure of snow slopes. Simulation Series, 15(1), $29-33$.

Williams, K. 1978. Post-control avalanche releases. In Association Nationale pour L'Etude de la Neige et des Avalanches. Deuxième Rencontre Internationale sur la Neige et les Avalanches, $12-13$ et 14 avril, 1978, Grenoble, France. Comptes rendus. Grenoble, ANENA, 251 263. 